\title{
Factors associated with changing efficacy of emamectin benzoate against infestations of Lepeophtheirus salmonis on Scottish salmon farms
}

\author{
F Lees ${ }^{1,2}$, M Baillie ${ }^{2}$, G Gettinby ${ }^{1}$ and C W Revie ${ }^{2}$ \\ 1 Department of Statistics and Modelling Science, University of Strathclyde, Glasgow, UK \\ 2 Department of Computer and Information Sciences, University of Strathclyde, Glasgow, UK
}

Keywords: efficacy, emamectin benzoate, Lepeophtheirus salmonis, Salmo salar L., Scotland.

The availability and use of medicines to control infestations of sea lice on Atlantic salmon, Salmo salar L., farms in Scotland has changed considerably in the last decade (Lees, Gettinby \& Revie 2008b). Whereas hydrogen peroxide and organophosphate compounds were used widely throughout the 1990s and in the early 2000s, only two therapeutants have remained in common use since 2005: topical cypermethrin (Excis ${ }^{\circledR}$; Novartis Animal Health, Camberley, UK) and an oral formulation of emamectin benzoate $\left(\right.$ SLICE $^{\circledR}$; Schering Plough Animal Health, Uxbridge, UK).

Although Excis $^{\circledR}$ and SLICE $^{\circledR}$ are effective against the two major species of sea lice that parasitize Atlantic salmon on Scottish farms, i.e. Lepeophtheirus salmonis (Krøyer, 1837) and Caligus elongatus (Nordmann, 1832), reliance on such a limited range of therapeutants has raised concerns that resistance in lice will become an increasing problem unless new medicines become available and/or existing treatments are carefully managed (Denholm, Devine, Horsberg, Sevatdal, Fallang, Nolan \& Powell 2002). These concerns are felt not only in Scotland, but also in other salmon produc ing countries where the choice of sea lice therapeu

Correspondence CW Revie, Department of Computer and Information Sciences, University of Strathclyde, Richmond Street, Glasgow G1 1XH, UK

(e mail: crawford.revie@cis.strath ac.uk) tants is limited (Westcott, Hammell \& Burka 2004). Indeed, in recent years, there have been anecdotal reports of reduced sensitivity of sea lice to emamectin benzoate, particularly amongst Caligus rogercresseyi Boxshall \& Bravo, 2000, populations in Chile (S. Bravo, personal communication).

Since gaining UK Marketing Authorization in 2000 the use of SLICE $^{\circledR}$ has risen dramatically on Scottish salmon farms not least because, as an in feed medicine, it offers several advantages in terms of application over topical treatments. However, the key benefit of SLICE $^{\circledR}$ is that it can provide sustained periods of louse clearance (Stone, Sutherland, Sommerville, Richards \& Endris 2000; Stone, Sutherland, Sommerville, Richards \& Varma 2000; Treasurer, Wallace \& Dear 2002). Two contemporary studies carried out in Maine (Gustafson, Ellis, Robinson, Mare nghi \& Endris 2006) and in British Columbia (Saksida, Constantine, Karreman \& Donald 2007) provided a snapshot of SLICE ${ }^{\circledR}$ treatment efficacy against infestations of $L$. salmonis in their respective regions. While these studies showed that, overall, SLICE ${ }^{\circledR}$ continues to provide lengthy periods of louse clearance in North America, neither report attempted to demonstrate whether efficacy had changed in the period since regular application of the medicine began.

A recent study examining the efficacy of SLICE ${ }^{\circledR}$ treatments against infestations of mobile $L$. salmonis on Scottish farms, in the period 20022006 (Lees, Baillie, Gettinby \& Revie 2008a), showed that not all treatment interventions were equally effective. 
Specifically, there appeared to be evidence of variation between geographical regions and a reduction in efficacy over time. This short commu nication builds on the previous study (Lees et al. 2008a) by further examining the apparent reduc tion in treatment efficacy.

Sea lice abundance, treatment and site stocking data were drawn from 56 Atlantic salmon farms located along the West coast of Scotland between 2002 and 2006. Sites on the Scottish mainland were divided above and below $57^{\circ} \mathrm{N}$ and are referred to as 'North' and 'South'. Sites referred to as 'Western Isles' include those on the East coast of South Uist and the East \& West coasts of Harris and Lewis. All farms were owned and managed by Marine Harvest (Scotland). Site wide treatment episodes, where SLICE ${ }^{\circledR}$ was the only sea lice medicine administered and where all pens began treatment on the same day were analysed $(n=185)$. As described in the previous study (Lees et al. 2008a), these treatment episodes were screened to establish whether sufficient lice count data were available in the weeks prior to and following treatment to allow further analysis $(n=108)$. In addition, 26 treatments that were administered before guideline treatment trigger levels had been reached (i.e. mean abundance of L. salmonis adult females $<0.5$ February June, or $\geq 1.0$ between July and January) were screened out. This resulted in a final data set of 82 treatment episodes administered across 40 farms.

Using the available lice count data, post treat ment L. salmonis abundance in the 12 weeks (83 days) following treatment intervention was examined as mean mobile lice per fish; and as a percentage of pretreatment abundance based on matched pre and post treatment lice counts (mean post treatment abundance/mean pretreatment abundance $\times 100)$. Treatments were then classified as 'effective' ( $n=63)$ or 'ineffective' $(n=19)$, with effective treatments defined as those where the mean abundance of mobile $L$. salmonis fell below $40 \%$ of pretreatment levels in at least one of the 12 weeks following treatment. A summary of all treatments included in the analysis is presented in Table 1.

In the previous study (Lees et al. 2008a), all treatment episodes were analysed regardless of whether they were classified as effective or not. However, as treatment episodes may be ineffective for a number of reasons unrelated to reduced sensitivity or resistance amongst lice populations,
Table 1 Numbers of effective and ineffective SLICE ${ }^{\circledR}$ treatment episodes on 40 Atlantic salmon farms in Scotland in the years 2002-2006

\begin{tabular}{lcrrrrr}
\hline & 2002 & 2003 & 2004 & 2005 & 2006 & Total \\
\hline Effective episodes & 9 & 15 & 20 & 15 & 4 & 63 \\
Ineffective episodes & 0 & 2 & 4 & 5 & 8 & 19 \\
Total & 9 & 17 & 24 & 20 & 12 & 82 \\
\hline
\end{tabular}

it was important to further examine underlying trends amongst only those treatment episodes deemed to be effective $(n=63)$. Figure 1a shows that, despite very different pretreatment lice burdens ranging from 18 lice per fish in 2003 to five in 2005, mean mobile abundance fell below 3.5 within 27 days of treatment initiation in all years. Mean abundance continued to fall to below 1.3 lice by day 55 .

The efficacy profiles (Fig. 1b) show that in 2002 and 2003 mean louse abundance fell to $10 \%$ of pretreatment levels within 20 days of treatment intervention and below 3\% by day 27 . Treatments applied in 2004 were also highly effective, with mean abundance falling to $6 \%$ of pretreatment levels by day 27 . In 2005, lice levels fell to $23 \%$ of pretreatment abundance within 27 days, continued to fall to $15 \%$ by day 55 , recovering gradually thereafter. In 2006, abundance as a proportion of pretreatment levels fell to $19 \%$ by day 27 and to $9 \%$ between days 28 and 34, however after this point it began to rise.

A general linear model was developed for the 63 effective treatment episodes. In addition to year of treatment, the model examined the effect of several other factors on post treatment mobile L. salmonis abundance and included pretreatment lice loads as a co variate (Table 2 ). To improve normality and equalize variances, data were logarithmically trans formed $[\ln (x+1)]$ prior to analysis. Least squares means and their 95\% confidence intervals (CI) are reported untransformed.

All factors were found to be significant and a significant interaction between region and days after treatment was observed (Table $2 \&$ Fig. 2). Post treatment abundance in 2005 was significantly higher than in 2002 and 2003, while in 2006 levels were significantly higher than in all previous years. Treatments administered in the autumn and winter months resulted in significantly higher post treatment lice levels compared with those applied in the spring and summer. Treatments administered on farms in the South region performed signifi 
Figure 1 (a) Mean mobile Lepeophtheirus salmonis abundance, pretreatment and 0-83 days after commencement of treatment. (b) Post-treatment mobile L. salmonis abundance as a percentage of pretreatment abundance, 7-83 days after commencement of treatment. Plots based on data from 63 effective treatment episodes at 36 Atlantic salmon farms in Scotland in the period 2002 2006.

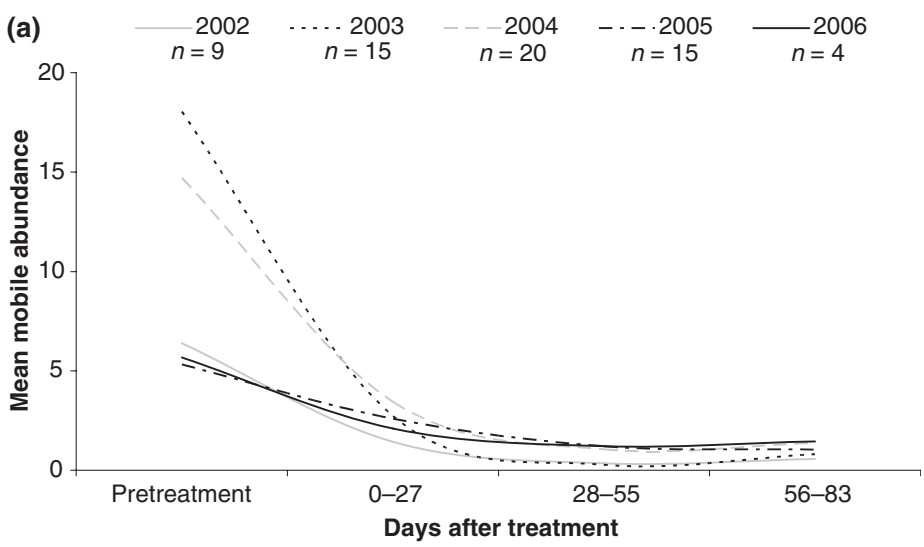

(b)

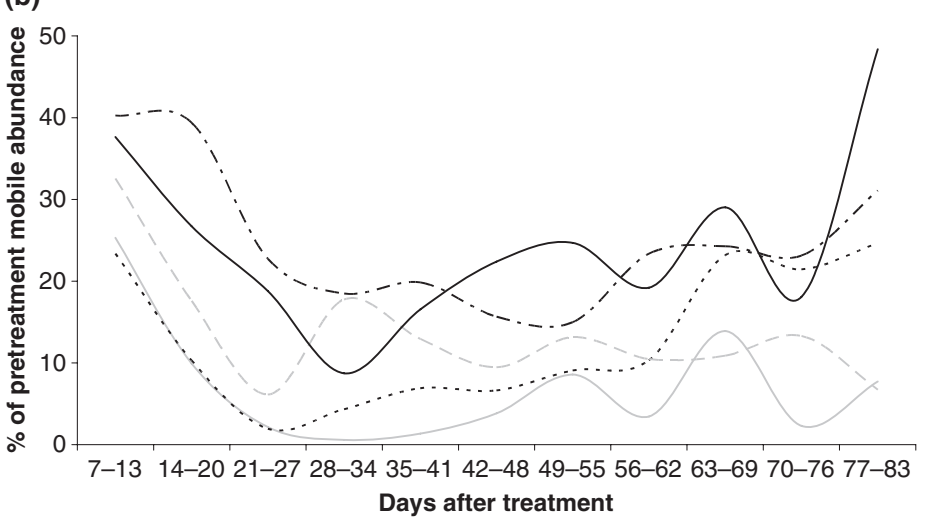

cantly less well than those in the North region and the Western Isles.

To examine the upward trend in ineffective treatment episodes between 2002 and 2006 (Table 1), a logistic regression model was developed to determine whether any factors were associated with ineffective treatment episodes (Table 3). All treatments given in 2002 were effective, therefore episodes administered in this year could not be included in the logistic model, leaving a total of 19 ineffective and 54 effective treatment episodes for analysis.

Table 3 shows the final logistic regression model that was developed and includes the factors that were found to be significant within the multivar iable analysis $(P \leq 0.05)$. The analysis shows that treatments given in 2006 were 11 times $(P=0.02$, CI 1.42 90.17) more likely to be ineffective than those given in 2003 and that winter treatments were also around 11 times $(P=0.01$, CI 1.6071 .73$)$ more likely to fail than those given in the spring. Pretreatment mobile lice abundance was included in the model as a forced co variate, however it was not found to be significant, indicating that lice levels prior to treatment intervention were not a factor in determining the success of a treatment. In addition, it was found that production year, geographical region, and whether the treatment was part of a loch wide intervention had no significant association with ineffective treatment episodes. Sensitivity analysis was carried out to assess the impact of revising the effective treatment episode criteria up or down from $40 \%$ of pretreat ment levels. Two additional logistic regression analyses were performed. In the first analysis, the cut off point for effective treatment episodes was lowered to $20 \%$ of pretreatment lice levels; in the second, the cut off point was increased to $50 \%$. In both analyses, year (2006) and season (winter) were once again found to be the only statistically significant factors.

It is acknowledged that the efficacy of in feed sea lice treatment episodes may be influenced by a number of factors relating to fish appetite, sub therapeutic dosing and concurrent disease. Further more, it should be noted that the apparent reduction in treatment efficacy reported herein occurred within a 5 year period when lice 


\begin{tabular}{|c|c|c|c|c|c|}
\hline \multirow[b]{2}{*}{ Factor } & \multirow[b]{2}{*}{$P$} & \multirow[b]{2}{*}{ Level } & \multicolumn{2}{|c|}{$\begin{array}{l}\text { Post treatment } \\
\text { mobile abundance }\end{array}$} & \multirow[b]{2}{*}{$\begin{array}{l}\% \text { of } \\
\text { treatments } \\
(n=63)\end{array}$} \\
\hline & & & $\begin{array}{l}\text { Least } \\
\text { squares } \\
\text { mean }\end{array}$ & $95 \% \mathrm{Cl}$ & \\
\hline $\begin{array}{l}\text { aPretreatment } \\
\text { mobile } \\
\text { abundance }\end{array}$ & 0.00 & & & & \\
\hline \multirow{11}{*}{$\begin{array}{l}\text { bDays after } \\
\text { treatment }\end{array}$} & 0.00 & 713 & 2.08 & 1.632 .62 & 65 \\
\hline & & 1420 & 1.21 & 0.891 .60 & 65 \\
\hline & & 2127 & 0.61 & 0.380 .88 & 71 \\
\hline & & 2834 & 0.69 & 0.440 .99 & 63 \\
\hline & & 3541 & 0.75 & 0.491 .05 & 68 \\
\hline & & 4248 & 0.73 & 0.461 .04 & 62 \\
\hline & & 4955 & 0.69 & 0.440 .97 & 68 \\
\hline & & 5662 & 0.90 & 0.611 .23 & 62 \\
\hline & & 6369 & 0.99 & $0.67 \quad 1.36$ & 57 \\
\hline & & 7076 & 0.99 & $0.67 \quad 1.37$ & 54 \\
\hline & & 7783 & 1.04 & 0.711 .43 & 54 \\
\hline \multirow[t]{3}{*}{ Region } & 0.00 & North & 0.73 & 0.540 .95 & 32 \\
\hline & & South & 1.43 & 1.181 .70 & 33 \\
\hline & & Western Isles & 0.73 & 0.570 .91 & 35 \\
\hline \multirow[t]{5}{*}{ Year } & 0.00 & 2002 & 0.46 & 0.260 .68 & 14 \\
\hline & & 2003 & 0.57 & $0.40 \quad 0.76$ & 24 \\
\hline & & 2004 & 0.81 & 0.640 .99 & 32 \\
\hline & & 2005 & 1.05 & 0.851 .29 & 24 \\
\hline & & 2006 & 2.22 & 1.593 .01 & 6 \\
\hline \multirow{2}{*}{ Production year } & 0.00 & First & 0.72 & 0.580 .88 & 43 \\
\hline & & Second & 1.18 & 0.961 .42 & 57 \\
\hline \multirow[t]{4}{*}{ Season } & 0.00 & $\begin{array}{l}\text { Spring } \\
\text { (Feb Apr) }\end{array}$ & 0.57 & 0.410 .75 & 35 \\
\hline & & Summer (May Jul) & 0.60 & $0.44 \quad 0.77$ & 27 \\
\hline & & $\begin{array}{l}\text { Autumn } \\
\text { (Aug Oct) }\end{array}$ & 1.13 & 0.921 .37 & 29 \\
\hline & & $\begin{array}{l}\text { Winter } \\
\text { (Nov Jan) }\end{array}$ & 1.64 & 1.172 .21 & 10 \\
\hline \multirow{2}{*}{ Loch wide } & 0.00 & No & 0.77 & 0.620 .92 & 62 \\
\hline & & Yes & 1.13 & 0.941 .33 & 38 \\
\hline $\begin{array}{l}\text { Region } \times \text { days } \\
\text { after treatment }\end{array}$ & 0.04 & See Fig. 2 & & & \\
\hline
\end{tabular}

Table 2 Results of the general linear model analysis of Lepeophtheirus salmonis abundance following SLICE ${ }^{\circledR}$ treatment. Results based on data from 63 effective treatment episodes at 36 Atlantic salmon farms in Scotland in the period 2002-2006

${ }^{\mathrm{a}}$ Forced co-variate with coefficient of 0.20 (95\% CI 0.13-0.28).

${ }^{b} \%$ of treatments for the variable 'Days after treatment' refers to the percentage of treated farms that were monitored for sea lice in each 7-day time period following treatment.

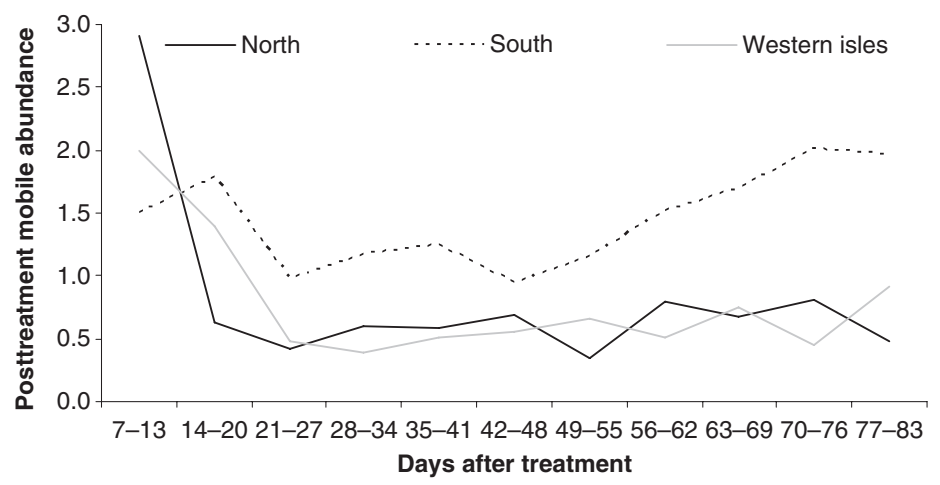

Figure 2 Profile plot showing the significant $(P<0.05)$ interaction between region and days after treatment. Post-treatment mobile abundances based on data from 63 effective treatment episodes at 36 Atlantic salmon farms in Scotland in the period 2002-2006.

abundance was found to be comparatively low (Lees et al. 2008b). Nevertheless, it is critical that the efficacy of this widely used sea lice medicine continues to be monitored closely and that fish health managers remain vigilant in reporting any apparent treatment failures. 
Table 3 Results of the logistic regression analysis of factors associated with ineffective SLICE ${ }^{\circledR}$ treatment episodes. Results based on data from 73 treatment episodes at 38 Atlantic salmon farms in Scotland in the period 2003-2006

\begin{tabular}{|c|c|c|c|c|c|c|}
\hline Factor & Level & Coefficient & SE Coefficient & $P$ & OR & $95 \% \mathrm{Cl}$ \\
\hline Constant & & 2.77 & 1.67 & 0.10 & & \\
\hline Pretreatment mobile abundance $[\ln (x+1)]$ & & 0.02 & 0.47 & 0.97 & 0.98 & 0.392 .46 \\
\hline \multirow[t]{3}{*}{ Year } & 2004 & 0.28 & 1.00 & 0.78 & 1.32 & 0.199 .40 \\
\hline & 2005 & 0.52 & 1.08 & 0.63 & 1.68 & 0.2013 .80 \\
\hline & 2006 & 2.42 & 1.06 & 0.02 & 11.30 & 1.4290 .17 \\
\hline \multirow[t]{3}{*}{ Season } & Summer & 0.52 & 1.07 & 0.63 & 1.69 & 0.2113 .79 \\
\hline & Autumn & 0.97 & 1.00 & 0.33 & 2.64 & $0.37 \quad 18.89$ \\
\hline & Winter & 2.37 & 0.97 & 0.01 & 10.72 & 1.6071 .73 \\
\hline
\end{tabular}

\section{Acknowledgements}

The database underpinning this work was created as part of two UK government funded research projects (MAFF LINK ENV12; DEFRA VM0213). Additional data analysis was supported by a grant from the Scottish Government (CR/2007/26). The industrial partner was Marine Harvest (Scotland). Thanks are due to all admin istrative and farm management staff who contrib uted to this project by collecting and providing access to production data. Particular thanks are due to the regional health managers.

\section{References}

Denholm I., Devine G.J., Horsberg T.E., Sevatdal S., Fallang A., Nolan D.V. \& Powell R. (2002) Analysis and management of resistance to chemotherapeutants in salmon lice, Lepeophtheirus salmonis (Copepoda: Caligidae). Pest Management Science 58, 528-536.

Gustafson L., Ellis S., Robinson T., Marenghi F. \& Endris R. (2006) Efficacy of emamectin benzoate against sea lice infestations of Atlantic salmon, Salmo salar L.: evaluation in the absence of an untreated contemporary control. Journal of Fish Diseases 29, 621-627.

Lees F., Baillie M., Gettinby G. \& Revie C.W. (2008a) The efficacy of emamectin benzoate against infestations of Lepeophtheirus salmonis on farmed Atlantic salmon (Salmo salar L.) in Scotland, 2002-2006. PLoS ONE 3, e1549. doi:10.1371/ journal.pone.0001549.
Lees F., Gettinby G. \& Revie C.W. (2008b) Changes in epidemiological patterns of sea lice infestation on farmed Atlantic salmon, Salmo salar L., in Scotland between 1996 and 2006. Journal of Fish Diseases 31, 259-268.

Saksida S., Constantine J., Karreman G.A. \& Donald A. (2007) Evaluation of sea lice abundance levels on farmed Atlantic salmon (Salmo salar L.) located in the Broughton Archipelago of British Columbia from 2003 to 2005. Aquaculture Research 38, 219-231.

Stone J., Sutherland I.H., Sommerville C., Richards R.H. \& Endris R.G. (2000) The duration of efficacy following oral treatment with emamectin benzoate against infestations of sea lice, Lepeophtheirus salmonis (Krøyer), in Atlantic salmon, Salmo salar L. Journal of Fish Diseases 23, 185-192.

Stone J., Sutherland I.H., Sommerville C., Richards R.H. \& Varma K.J. (2000) Commercial trials using emamectin benzoate to control sea lice Lepeophtheirus salmonis infestations in Atlantic salmon Salmo salar. Diseases of Aquatic Organisms 41, 141-149.

Treasurer J.W., Wallace C. \& Dear G. (2002) Control of sea lice on farmed Atlantic salmon, S. salar L., with the oral treatment emamectin benzoate $\left(\right.$ SLICE $\left.^{\circledR}\right)$. Bulletin of the European Association of Fish Pathologists 22, 375-380.

Westcott J.D., Hammell K.L. \& Burka J.F. (2004) Sea lice treatments, management practices and sea lice sampling methods on Atlantic salmon farms in the Bay of Fundy, New Brunswick, Canada. Aquaculture Research 35, 784-792. 